\title{
The Blood Cells Ultrastructure Electron Microscopy Changes: Reflection on Systemic Lupus Erythematosus
}

Eman Mohamed Faruk ${ }^{* 1}$, Rania Ebrahim Eldesoky ${ }^{1}$, Marwa Yahia Mahgoub ${ }^{2}$, Enas Mohamed Mahmoud El.gndy ${ }^{1}$ and Hanan Fouad ${ }^{3}$

${ }^{1}$ Department Histology and Cell Biology, Faculty of Medicine, Benha University, Egypt

${ }^{2}$ Department of Rheumatology, Rehabilitation and Physical medicine, Faculty of Medicine, Benha University, Egypt

${ }^{3}$ Department of Medical Biochemistry, Faculty of Medicine, Cairo University, Egypt

*Corresponding author: Faruk EM, Department Histology and Cell Biology, Faculty of Medicine, Benha University, Egypt, Tel: 0020133221937; E-mail: faruk_eman@yahoo.com

Received date: February 12, 2019; Accepted date: February 22, 2019; Published date: February 28, 2019

Copyright: () 2019 Faruk EM, et al. This is an open-access article distributed under the terms of the Creative Commons Attribution License, which permits unrestricted use, distribution, and reproduction in any medium, provided the original author and source are credited.

\begin{abstract}
The sub-laboratory effects of SLE on blood cells were not completely evaluated to explain the thrombotic tendency found in this disease. The present study was conducted to assess the ultrastructural changes of RBCs, WBCs and platelets in SLE and to corelate these changes with the disease activity. Comet assay and 8hydroxydeoguanosine (8-OHdG) were used to confirm cellular dysfunction. Ninety subjects were recruited and equally divided into 3 groups: Group I; SLE (normal CBC), Group II; SLE (abnormal CBC) and Group III; healthy control. Disease activity was evaluated by systemic lupus erythematosus disease activity index score (SLEDAI). Ultrastructure examination of blood cells were done by electron microscope, DNA damage was assessed by Comet assay and serum 8-OHdG levels. CBC and serological tests including serum C3, C4, ANA and anti-dsDNA were evaluated. There was statistically significant negative correlation between RBCs and WBCs elements with SLEDAI score in Group II. There was significant statistical difference in RBCs and WBCs cell membrane defects by electron microscope between Group I and Group II. There was no statistically significant correlation between blood cell membrane defects and SLEDAI score in both Group I and Group II. There was a significant increase in percentage of tail DNA damage $(p<0.05)$ in Comet assay and serum $8-\mathrm{OHdG}$ levels in Group I and Group II. In conclusion, there are ultrastructural changes in blood cells in SLE that could play a crucial role in the thrombotic and inflammatory effects of blood cells. Comet assay can be used as a detectable and reliable method for assessment of other biological genetic research.
\end{abstract}

Keywords: Systemic lupus erythematosus; Blood cells; Transmission electron microscopy; Comet assay; 8-OHdG

\section{Introduction}

Systemic lupus erythematosus (SLE) is a chronic systemic inflammatory autoimmune disease. This clues to the production of proinflammatory cytokines, autoantibodies and immune complexes. Blood cells, kidney and central nervous system are the main target organs for immune complex-mediated inflammation $[1,2]$.

Deposition of complement (C3 and C4) fragments on RBCs membranes during the disease activity leads to cytoskeletal changes and defects in these cells. This augments their liability to destruction, their disturbances in the microcirculation, thrombosis and increase in fibrinogen plasma levels with subsequent erythrocyte aggregation $[3,4]$. Nitric oxide (NO) plays a crucial role in SLE regarding the pathophysiologic processes of the immune system dysregulation. NO leads to disturbances in the RBCs flow through the capillaries with negative effects on oxygen delivery to the tissues $[4,5]$.

Platelets are other targets for the activated complement system in SLE [6,7]. This leads to the production of anti-phospholipid antibodies which are directed to the phospholipids of the platelets cell membrane leading to its destruction and thrombocytopenia [8]. Defects in the platelets cell membrane predispose to platelets aggregation and venous thrombosis [9].
Autoimmune inflammation also targets white blood cells (WBCs). Circulating anti-neutrophil antibodies lead to destruction of the neutrophils [11]. Neutrophils also plays a leading role in thrombosis because anti-phospholipid antibodies cooperate with neutrophilic cytokines leading to thrombosis $[12,13]$.

The Comet Assay or single cell gel electrophoresis assay is widely used method to assay the microscopically DNA damage in a single cell. The visual scoring of cells is used to determine the DNA damage as classified according to tail length, the shape, size of DNA and its amount, all of above can determine the level of DNA damage [14].

The current study was conducted to assess the ultrastructure of RBCs, WBCs and platelets in SLE to evaluate the sub-laboratory affections of blood cells and to corelate these changes with the disease activity. Comet assay and 8-hydroxydeoguanosine (8-OHdG) were also assessed to confirm cellular dysfunction.

\section{Method}

The present cross-sectional study was conducted on 60 SLE patients. Patients were carefully selected and equally divided into two groups: Group I ( $n=30)$ SLE patients with normal CBC, Group II ( $n=30)$ SLE patients with abnormal CBC. Group III $(n=30)$ included healthy subjects enrolled as control group.

All patients attended to Rheumatology, Rehabilitation and Physical Medicine Department inpatients and outpatients' clinics, Benha 
University Hospitals from September 2015 to May 2017. Written informed consent forms were obtained from all patients. The study complies with the guidelines for human studies and animal welfare regulations. The study protocol has been approved by the institute's ethical committee on human research and meets the standards of the Declaration of Helsinki in its revised version of 1975 and its amendments of 1983, 1989, and 1996 [15].

All patients were diagnosed according to Systemic Lupus International Collaborating Clinics (SLICC) criteria for diagnosis of SLE patients [16]. Clinical history and clinical examination were obtained from all patients. SLE disease activity was assessed according to systemic lupus erythematosus disease activity index score (SLEDAI) to mild (score: 0-10), moderate (score: 11-20), severe (score: 21-45) and very severe (score $>45)$ [17].

Venous blood samples were collected from all subjects and the following parameters measured: complete blood count, electron microscope analysis, serum creatinine, creatinine clearance, Antinuclear antibody (ANA) by immunofluorescence technique, Antidouble stranded DNA (dsDNA) antibody by indirect fluorescent antibody test, complement $\mathrm{C} 3$ and $\mathrm{C} 4$, C-reactive protein (CRP), erythrocyte sedimentation rate (ESR), Comet assay, and 8hydroxydeoxyguanosine (8-OHdG). Twenty-four hours' urine and spot urine sample were collected to estimate urinary protein excretion.

\section{Ultrastructure analysis by transmission electron microscope}

Blood samples were collected from all groups in heparinized tubes ( $2 \mathrm{~mL}$ of blood) then centrifuged at $500 \mathrm{~g}$ for $5 \mathrm{~min}$ at room temperature. A layer of white blood cells and thrombocytes plus a small portion of the red blood cells layer were removed and fixed in a $2 \%$ glutaraldehyde solution in phosphate buffered saline (PBS) for 90 min. The fixed cells sediment was centrifuged at $1000 \mathrm{rpm}$ for $10 \mathrm{~min}$ and washed with PBS three times for 15 minutes. The samples were added to buffered $2 \%$ osmium tetroxide as secondary fixative for 4 hours then were washed three times in distilled water for 15 minutes and left 4 hours in $1 \%$ uranyl acetate solution. Samples were dehydrated in ethanol $(20 \%, 40 \%, 60 \%, 70 \%, 100 \%$ series $)$ and passed through ethanol-propylene oxide, propylene oxide and propylene Oxide-Embed 812 resins. Samples were polymerized in fresh Embed resin, and were cut on an ultramicrotome (Reichert, Bensheim, Germany). Finally, the sections were stained with uranyl acetate. Sections were examined with transmission electron microscope and images were taken with an EM digital camera system (MegaView, analysisc docu 3.2, Olympus Soft Imaging Systems GmbH, Munster, Germany) according to Winey et al. [18].

\section{Serum 8-OHdG Levels measurement}

Serum 8-OHdG levels were measured using a commercially available enzyme-linked immunosorbent assay kit (Abcam, England, catalogue No. ab201734).

\section{Single cell gel electrophoresis assay (Comet assay)}

The DNA damage was detection done by using the single-cell gel electrophoresis (Comet assay) "a sensitive and powerful method for determining DNA strand breakage" [19].

In Eppendorf tubes $1 \mathrm{ml}$ of lymphocyte and WBC suspensions were transferred and centrifuged at $2000 \times \mathrm{g}$ for $5 \mathrm{~min}$. The supernatant was cleaned, and the cell pellet was mixed with $500 \mathrm{ml}$ of low-melting- point (LMP) agarose in phosphate-buffered saline (PBS) at $37^{\circ} \mathrm{C}$. Then this mixture was applied onto a glass microscope slide. Whole blood was used directly for comet assay, in which $20 \mathrm{ml}$ of whole blood was mixed with $150 \mathrm{ml}$ of LMP agarose, and $140 \mathrm{~mL}$ of the mixture was applied onto a glass microscope slide pre-coated with a layer of $1 \%$ normal melting-point agarose $(150 \mathrm{ml})$. After application of a third layer of $1 \%$ normal-melting point agarose $(150 \mathrm{ml})$, the slides were immersed in ice-cold-lysing solution ( $2.5 \mathrm{mg}$ sodium chloride, $10 \mathrm{ml}$ Tris, $100 \mathrm{~mL}$ Ethylenediaminetetraacetic acid (EDTA), 10\% dimethyl sulfoxide, $1 \%$ Triton X-100, $\mathrm{pH} 10.0$ ) for at least 2 hours. The slides were then incubated in ice-cold electrophoresis solution $(0.3 \mathrm{mg}$ sodium chloride, $1 \mathrm{ml}$ EDTA, $\mathrm{pH}$ 13.0) for $20 \mathrm{~min}$, followed by electrophoresis at $15 \mathrm{~V}$ for $25 \mathrm{~min}$ allowing the DNA to unwind for 15 min in the alkaline solution ( $300 \mathrm{~mm} \mathrm{NaOH}$ and $1 \mathrm{~mm} \mathrm{Na} \mathrm{NaDTA}_{2}$. After electrophoresis, the slides were neutralized and stained with ethidium bromide. Fluorescence microscope (Leica DM-2500) was used to analysis of comets, and the percentage tail DNA was calculated based on (\% tail DNA = $100-\%$ head DNA) for the quantification of DNA damage and the assessment of length of the DNA migration (i.e., diameter of the nucleus plus migrated DNA) was measured using image analysis Axiovision 3.1 software (Carl Zeiss, Canada) [20].

\section{Collection of whole blood and isolation of lymphocytes}

The $10 \mathrm{ml}$ blood was obtained from all groups in tube containing $\mathrm{K}_{3}$ - EDTA. Lymphocytes were isolated by a modified procedure previously described. Briefly, $3 \mathrm{~mL}$ of whole blood was diluted 1:1 with RPMI and carefully layered on the top of lymphocyte separation medium in a centrifugation tube in a ratio of $1: 1$ for $15 \mathrm{~min}$. The white layer of lymphocytes between plasma and the medium was then transferred by Pasteur pipette in $5 \mathrm{ml}$ of culture media, RPMI. Then lymphocytes were then washed twice with RPMI and centrifuged at $250 \times \mathrm{g}$ for $10 \mathrm{~min}$. Then the cell pellet was put in $6 \mathrm{~mL}$ of RPMI containing no FBS (ca. $5.2 \times 10^{5}$ lymphocytes $/ \mathrm{ml}$ medium), and $1 \mathrm{ml}$ of the suspension was used for comet assay or for in vitro incubation. Cell viability determined using the Trypan blue assay [21].

\section{Isolation of white blood cell from fresh blood}

WBCs were separated using a modified version of the procedure [22]. In which $3 \mathrm{ml}$ of whole blood collected in K3-EDTA-containing was centrifugation at $2000 \times \mathrm{g}$ for $5 \mathrm{~min}$ and diluted $1: 3$ with $\mathrm{RBC}$ lysis buffer (0.15 M NH 4 Cl, 12 mM NaHCO $3,0.16 \mathrm{mM} \mathrm{Na}_{2}$ EDTA, pH 7.0). The tube was inverted to mix well and incubated $5 \mathrm{~min}$ at room temperature then centrifuged $(2000 \times \mathrm{g}, 5 \mathrm{~min})$, and the supernatant was removed, leaving only the visible WBC pellet. Five milliliters of $\mathrm{RBC}$ lysis solution were then added to resuspend the WBCs, the last step was repeated at least twice to clear all RBCs. After centrifugation, the cells were suspended in $6 \mathrm{ml}$ of RPMI containing no FBS (ca. $9 \times$ $10^{6}$ cells $/ \mathrm{mL}$ ). For comparison between groups we used slide prepared from damaged cells that known to containing amount of DNA damage to avoid variation that can occur during the measurements of DNA damage.

\section{Statistical analysis}

Statistical analyses were carried out using Microsoft excel 2013 (Microsoft Egypt, Cairo, Egypt). Clinical data are expressed as mean and standard deviation (SD), T-test was used to determine statistical differences, Chi-squared test for proportion correlations and a p-value $<0.05$ was considered statistically significant. 
Citation: Faruk EM, Eldesoky RE, Mahgoub MY, Mahmoud El.gndy EM, Fouad H (2019) The Blood Cells Ultrastructure Electron Microscopy Changes: Reflection on Systemic Lupus Erythematosus. J Cytol Histol 10: 534. doi:10.4172/2157-7099.1000534

Page 3 of 7

\section{Results}

Our subjects were all females and assembled to group I included 30 SLE patients without laboratory evidence of haematological manifestation (mean age $26.97 \pm 6.44$ ), group II included 30 SLE patients with laboratory evidence of haematological manifestation (mean age 27.37 \pm 5.90 ), and group III healthy control group included 30 healthy females (mean age 26.5 \pm 4.5 ). The clinical and laboratory characteristics are presented in Table 1.
Our data revealed statistically significant negative correlation between $\mathrm{CBC}$ and WBCs counts with SLEDAI score in Group II whereas, there was no statistically significant correlation regarding platelets count. Moreover, there was no significant correlation between SLEDAI and blood elements counts in Group I (Table 2).

\begin{tabular}{|c|c|c|}
\hline Parameter & Group I & Group II \\
\hline Disease duration & $1.5 \pm 0.8$ & $3.27 \pm 2.67$ \\
\hline mucocutaneous manifestation & $90 \%$ & $57 \%$ \\
\hline Synovitis & $15 \%$ & $10 \%$ \\
\hline Serositis & $83.3 \%$ & $30 \%$ \\
\hline Renal & $10 \%$ & $86.6 \%$ \\
\hline Neurologic & $0 \%$ & $3.3 \%$ \\
\hline anemia & $0 \%$ & $90 \%$ \\
\hline Leukopenia & $0 \%$ & $50 \%$ \\
\hline Thrombocytopenia & $0 \%$ & $16.6 \%$ \\
\hline ANA & $100 \%$ & $100 \%$ \\
\hline Anti-dsDNA & $3.3 \%$ & $86.6 \%$ \\
\hline Low complement & $0 \%$ & $20 \%$ \\
\hline \multirow{5}{*}{ SLEDAI Score } & $70 \%$ mild & $16.6 \%$ mild \\
\hline & & $50 \%$ moderate \\
\hline & $30 \%$ moderate & \\
\hline & & $33.3 \%$ severe \\
\hline & - & \\
\hline
\end{tabular}

Table 1: Clinical and serological characteristics of patients at the time of the study.

\begin{tabular}{|c|c|c|}
\hline \multirow[t]{2}{*}{ Parameter } & \multicolumn{2}{|l|}{ SLEDAI } \\
\hline & Group I & Group II \\
\hline \multirow[b]{2}{*}{ RBCS } & $r=0.44822$ & $r=-0.90$ \\
\hline & $p=0.19839$ & $p<0.001^{*}$ \\
\hline \multirow[b]{2}{*}{ WBCs } & $r=-0.03712$ & $r=-0.8530$ \\
\hline & $p=0.9137$ & $p<0.001^{*}$ \\
\hline \multirow[b]{2}{*}{ Platelets } & $r=0.43021$ & $r=-0.9$ \\
\hline & $p=0.18659$ & $p=0.2$ \\
\hline
\end{tabular}

Table 2: Correlation between CBC elements and SLEDAI score in group I and II. 
Citation: Faruk EM, Eldesoky RE, Mahgoub MY, Mahmoud El.gndy EM, Fouad H (2019) The Blood Cells Ultrastructure Electron Microscopy Changes: Reflection on Systemic Lupus Erythematosus. J Cytol Histol 10: 534. doi:10.4172/2157-7099.1000534

Page 4 of 7

\section{Electron microscopic results}

Ultrastructure of blood cells from control group revealed normal appearance of the blood cells in which Neutrophil showed many granules within the cytoplasm and lobed nucleus (Figure 1a). A basophil showed irregular round nucleus with sparse chromatin and eccentric nucleoli with heterogenous granules in the cytoplasm (Figure 1b). Whereas, an eosinophil cell showed segmented nucleus with condensed chromatin and its cytoplasm embedded with enormous number of granules of different shapes, electron- density crystalloid structure was easily identified (Figure 1c). A monocyte showed large indented nucleus and less electron dense cytoplasm (Figure 1d). A lymphocyte revealed nuclear indentation (Figure 1e). Platelet contains intracellular organelles in its cytoplasm and contains granules, but no nucleus (Figure 1f).

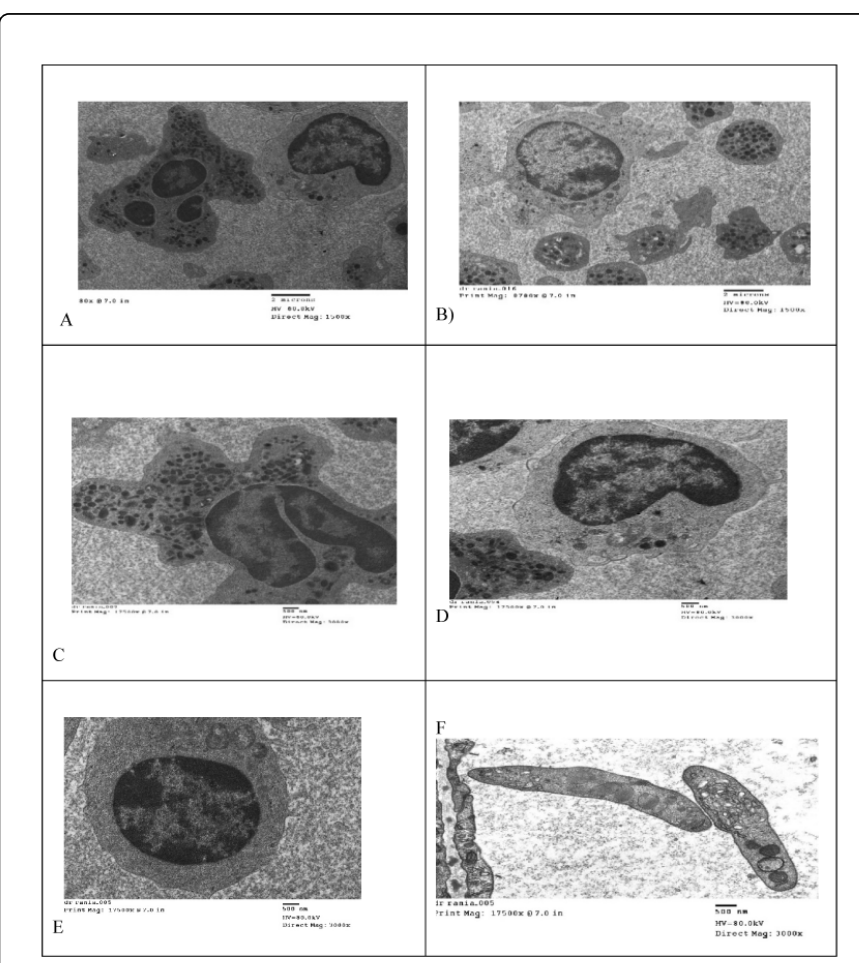

Figure 1: A transmission electron micrograph from a control group presenting A) a neutrophil with lobulated nucleus (n) and cytoplasmic granules $(\mathrm{g})$ TEM $\times 17500$. B) A basophil showing round eccentric nucleus covered by cytoplasmic granules (g) TEM $\times 8780$. C) An eosinophil with a cytoplasm filled with crystalcontaining granules (g), and a segmented nucleus with heavily condensed chromatin, $(n)$ TEM $\times 17500$. D) A monocyte showing deep indented nucleus (arrow) and less electron dense cytoplasm. E) A lymphocyte revealed nuclear indentation $(n)$ TEM $\times 17500$. F) platelets contain cytoplasm with some intracellular organelles (arrow). Note no nucleus. TEM $\times 17500$.

The ultrastructure of blood cells that obtained from SLE patient in group I showed moderate changes in the blood cells in which there is less electron dense cytoplasm in neutrophil (Figure 2a), a basophil showing vacuolated cytoplasm (Figure 2b), Eosinophil showing irregular membrane with heterochromatic nuclei and cytoplasmic granule (Figure 2c), Monocyte showing less electron density with less distinct organelles (Figure 2d), Lymphocyte showing irregular nucleus with irregular membrane (Figure 2e). Loss of discoid shape of platelets, vacuolated cytoplasm, and prominent Golgi structures (Figure 2f).

The ultrastructure of blood cells that obtained from SLE patient in Group II revealed marked alterations in the morphology of all blood elements. The nuclei showed less heterochromatin content and several nuclear envelope blebs. Vacuolated less electron dense cytoplasm was noticed and slightly irregular outline with less distinct organelles. (Figure 3).

There was significant statistical difference in RBCs and WBCs cell membrane defects by electron microscope between Group I and Group II (Table 3). There was no statistically significant correlation between blood cell membrane defects and SLEDAI score in both Group I and Group II (Table 4).

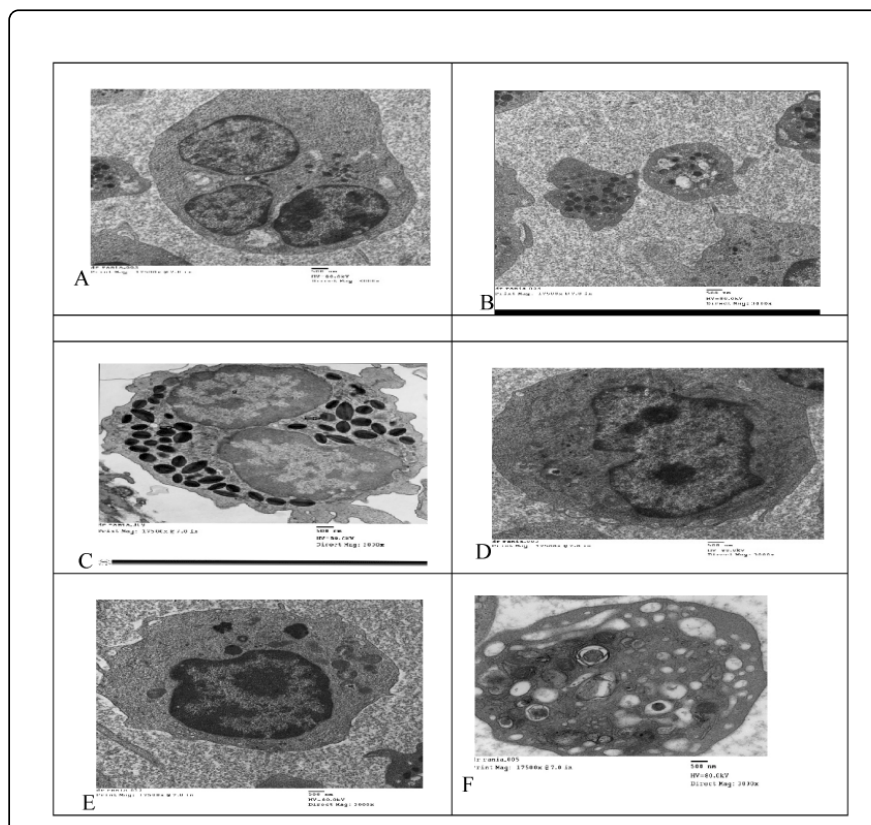

Figure 2: A transmission electron micrograph from SLE patients in group I show A) a neutrophil showing less electron dense cytoplasm (C). Note absence of microvilli (arrow). B) A basophil showing vacuolated cytoplasm $(v)$ TEM $\times 17500$. C) eosinophilia showing irregular membrane with heterochromatic nuclei(g). Note cytoplasmic granule (arrow). TEMx17500. D) monocyte showing less electron density with less distinct organelles (arrow). TEM $\times 17500$. E) A lymphocyte irregular nucleus with irregular membrane (arrow). TEM $\times 17500$. F) loss of discoid shape of palette, vacuolated cytoplasm, (arrow). Note presence of Prominent Golgi structures $(\mathrm{G})$. TEM $\times 17500$. 
Citation: Faruk EM, Eldesoky RE, Mahgoub MY, Mahmoud El.gndy EM, Fouad H (2019) The Blood Cells Ultrastructure Electron Microscopy Changes: Reflection on Systemic Lupus Erythematosus. J Cytol Histol 10: 534. doi:10.4172/2157-7099.1000534

Page 5 of 7

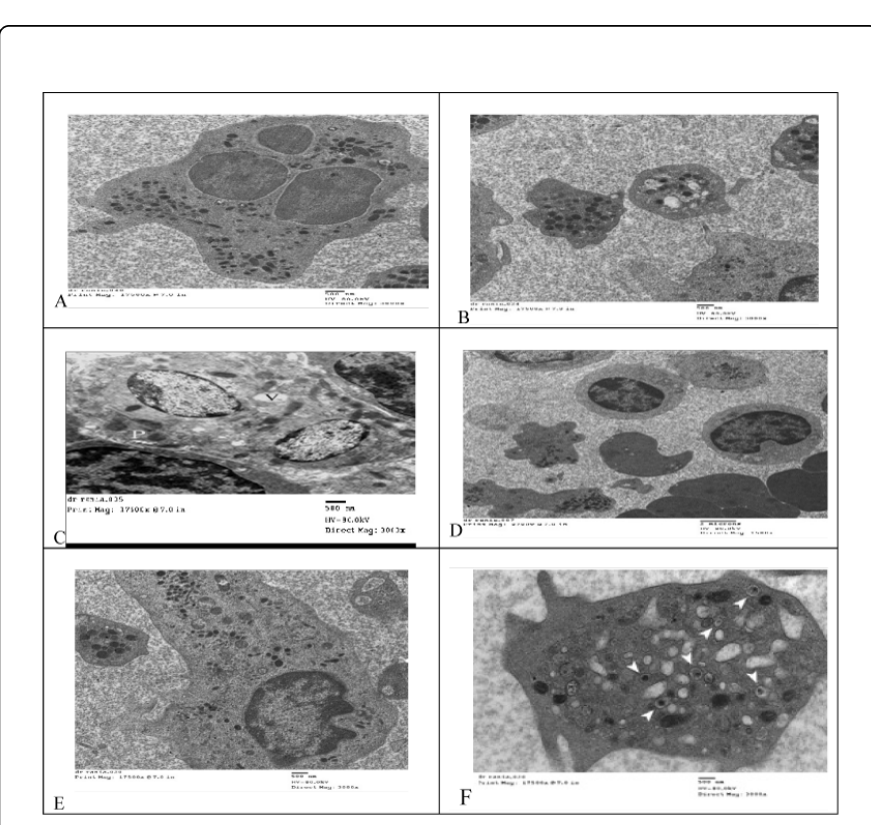

Figure 3: A transmission electron micrograph from SLE patients in group II showing A) a neutrophil showing less electron dense cytoplasm (arrow) with less heterochromatic nuclei(n) B) A basophil showing vaculations (arrow) and sparse cytoplasmic granules $(g)$ TEM $\times 17500 . C)$ eosinophil showing vacuolated $(V)$ cytoplasm containing specific granules without central crystals (arrow). TEMx17500. D) monocyte showing less electron density with less distinct organelles (arrow). TEM $\times 8780$. E) A lymphocyte irregular nucleus (arrow). TEM $\times 8780.5)$ Irregular membrane, vacuolated cytoplasm, disappearance of cytoplasmic granules (arrows head) TEM $\times 17500$.

\begin{tabular}{|l|l|l|l|}
\hline EM changes & Group I (30) & Group II (30) & p value \\
\hline RBCS & $(50 \%)$ & $(83.3 \%)$ & 0.006 \\
\hline WBCs & $(33.3 \%)$ & $(66.7 \%)$ & 0.01 \\
\hline Platelets & $(23.3 \%)$ & $(33.3 \%)$ & 0.4 \\
\hline
\end{tabular}

EM: electron microscope, RBCs: Red Blood Cells, WBCs: White blood cells.

Table 3: comparison between the studied groups according to EM findings and the number of patients.

\begin{tabular}{|l|l|l|l|}
\hline Groups & SLEDAI & EM & p-value \\
\hline Group I & Mild $70 \%$ & $50 \%$ & 0.11 \\
\hline & Moderate $30 \%$ & $23.3 \%$ & 0.56 \\
\hline Group II & Mild $16.6 \%$ & $13.3 \%$ & 0.72 \\
\hline & Moderate $50 \%$ & $40 \%$ & 0.44 \\
\hline & Severe $33.3 \%$ & $26.6 \%$ & 0.57 \\
\hline
\end{tabular}

SLEDAI: Systemic Lupus Erythematosus Disease Activity Index, EM: electron microscope.

Table 4: Correlation between EM blood cells changes and score in group I and II.

\section{Serum 8-OHdG level}

There was no statistically significant difference between group I and group II, but there was a significant difference between each patient group and the control group (Table 5).

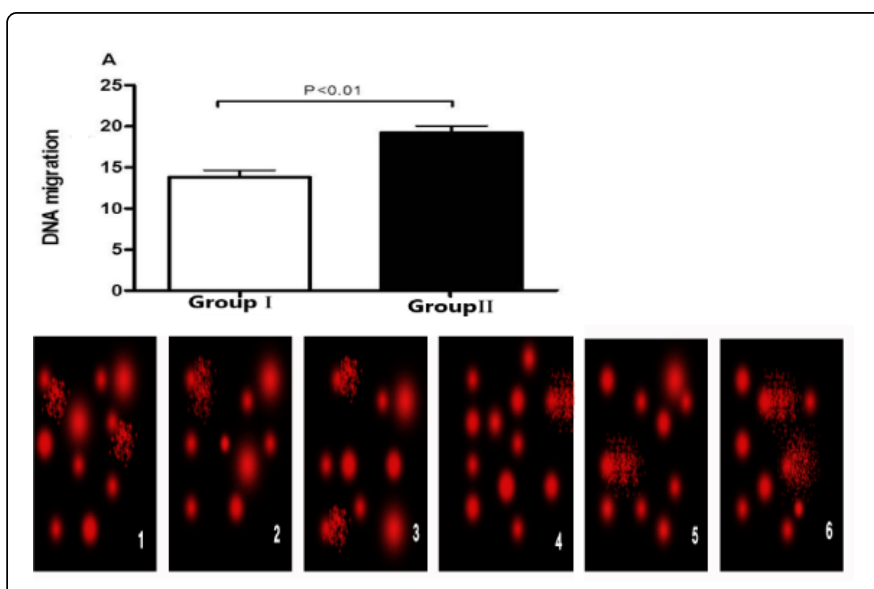

Figure 4: DNA migration $(\mathrm{mm})$ in the blood cells assessed by Comet assay in group I and group II (A). Data are means \pm SEM $(n=5) . B)$ Representative images illustrating the quantification of the DNA migration by the Comet assay. There were significant differences in Group I and group II DNA strand breaks between lymphocytes and whole blood in control group (1 and 2), group I(3 and 4) and group II(5 and 6).

\begin{tabular}{|l|l|l|l|}
\hline Parameter & Group I & Group II & Control (III) \\
\hline 8-OHdG ng/mL & $295.5 \pm 34.7$ & $343.5 \pm 39.6$ & $95.5 \pm 32.1$ \\
\hline Note: P I\&III < 0.0001, P II\&III < 0.0001 and P \&\& II 0.295. 8-OHdG: 8-hydroxydeoguanosine. \\
\hline
\end{tabular}

Table 5: Levels of Serum Levels of 8-OHdG in all groups.

\section{Comet assay of DNA (tail DNA migration)}

There was significant remarkable increase in percentage of tail DNA damage in Comet assay in Group I and Group II in comparison to control $(\mathrm{p}<0.05)$. The percentage of tail DNA damage was significantly elevated in Group II in comparison to Group I ( $p<0.01$ ) (Figure 4). 


\section{Discussion}

Despite of several treatment strategies used in SLE, recurrent exacerbation attacks supervene all through patients' lives. Various continuous symptoms frequently retard the patient daily activities. Headache, pain, fatigue, delirium, and many constitutional symptoms are unbounded complains in lupus patients [23]. SLE is characterized by ongoing complement activation followed by deposition of complement fragments on circulating blood cells. The deformed blood cells by complement fragment have limited circulation and functions [23]. The ongoing pathogenesis in blood cells may contribute to all these symptoms. So, the present study was conducted to investigate the ultrastructure and cytogenetic changes of blood elements in SLE patients.

Focusing on the blood cells function, we used electron microscopy to detect the sub laboratory changes of blood cells which we considered that it is more accurate methodology in assessing the cell membrane changes as a site of the pathogenesis rather than assessing only blood cells counts. Also, we used Comet assay to notice DNA abnormalities and measured 8-OHdG serum levels to illuminate the defects of oxygen delivery by the distorted cells.

Ultrastructure results demonstrated noticeable alterations in the morphology of blood cells, in which the nuclei showed less heterochromatin content and several nuclear envelope blebs. Vacuolated less electron dense cytoplasm was revealed and slightly irregular outline. These findings were in group I and group II with more obvious changes on group II but no significant differences between the disease groups whereas there was statistically significant difference between both patient groups in comparison to the control group. SLEDAI score was not sensitive enough to reveal the sub laboratory changes of blood cells in Group I with normal CBC because it depends on the number of the blood cells and not the function. Whereas, significant negative correlation was noticed between blood element defects and SLEDAI score in Group II. Our findings agreed with previous studies which revealed that the deposition of C 3 and C4 complement fragments on the erythrocyte membranes is a link between decreased membrane deformability, tissue hypoxia and SLEspecific organ damage [24]. It was stated in another study that SLE patients have inflammatory ultrastructural changes in their blood elements [4]. Deformed platelets show blebbing, formation of microparticles and fusion with the erythrocyte membranes. Platelets interact actively with other inflammatory cells as white blood cells (WBCs). Concerted interactions of platelets, WBCs and erythrocytes inside the inflammatory fibrin networks predispose to the prothrombotic states in SLE patients [9].

As regards serum 8-OHdG level, there was statistically significant elevation between both patient groups in comparison to the control group. Comet assay revealed that the degradation of nuclear DNA in lymphocytes of SLE was seen to occur at elevated percentage. Comet test and 8-OHgG serum levels results confirmed the study hitting point where findings in group II were significantly higher than results of group I.

These observations could be explained by the fact that defects in the cell membrane lead to decreased ability of RBCs to deliver oxygen to the tissues [25]. Our findings in SLE patients of the diminished membrane deformability in RBCs, in association with chronic anemia, could explain some of the constitutional symptoms of patients with SLE such as chronic fatigue [26]. Another explanation is that the damaged blood cells lead to the release free radicals which cause damage vascular endothelial cells and smooth muscle cells [27]. Accumulation of the altered base, $8-\mathrm{OHdG}$, was proved to be a sensitive biomarker of reactive oxygen species-induced damage [28]. It was found that 8-OHdG accumulate in DNA and associate with the circulating immune complexes. Oxygen radicals induce chronic inflammatory state in SLE by maintaining the presence of the damaged antigenic form of DNA in the circulation [29].

Moreover, free radicals were also identified as a significant factor in inducing mitochondrial proliferation with hyperpolarization and induction of abnormal signaling pathways in T cells [30,31]. Higher oxidative stress with deficiency in DNA repair system, antioxidant enzymes and mitochondrial biogenesis may be implicated in SLE deterioration [32].

\section{Conclusion}

The current study described the ongoing pathological cytogenetic effect of SLE on blood cells with sub laboratory ultrastructure changes that could explain several pathogenic aspects of SLE manifestations. Therefore, blood cells changes are not only considered as SLE biomarker for early detection of subtle disease activity, but also an important therapeutic target for intercepting abnormal signaling. Limitations of the present study are: the small sample size, the missed declaration of our findings with different treatment lines and the nonquantitative data obtained from EM findings as there was no scoring methods used to interpret these findings.

\section{Acknowledgment}

The authors would like to thank the nurses in rheumatology department in Benha Hospital, Egypt.

\section{References}

1. Biolard E, Blanco P, Nigrovic A (2012) Platelets: active players in the pathogenesis of arthritis and SLE. Nature 8: 534-542.

2. Vikerfors A, Johansson AB, Gustafsson JT, Jonsen A, Leonard D, et al. (2013) Clinical manifestations and antiphospholipid antibodies in 712 patients with systemic lupus erythematosus: evaluation of two diagnostic assays. Rheumatology (Oxford) 52: 501-509.

3. Ponomarevaa AA, Nevzorova TA, Mordakhanova ER, Andrianova IA, Litvinov RI (2016) Structural characterization of platelets and platelet microvesicles. Tissue Biology 10: 217-226.

4. Ghiran IC, Zeidel ML, Shevkoplyas SS, Burns JM, Tsokos GC, et al. (2011) Systemic lupus erythematosus serum deposits C4d on red blood cells, decreases red blood cell membrane deformability, and promotes nitric oxide production. Arthritis Rheum 63: 503-512.

5. Mashhadi MA, Bari Z (2011) Thrombotic thrombocytopenic purpura and deep vein thrombosis as the presenting manifestations of systemic lupus erythematosus: a case report and review of literature. J Res Med Sci 16: $1082-1088$.

6. Boilard E, Blanco P, Nigrovic PA (2012) Platelets: active players in the pathogenesis of arthritis and SLE. Nat Rev Rheumatol 8: 534-542.

7. Satoh T, Tanaka Y, Okazaki Y, Kaburaki J, Ikeda Y, et al. (2012) Independent anti-platelet factor 4 autoantibodies in patients with systemic lupus erythematosus. Rheumatology (Oxford) 51: 1721-1728.

8. Hrycek A, Cies'lik P (2012) Annexin A5 and anti-annexin antibodies in patients with systemic lupus erythematosus. Rheumatol Int 32: 1335-1342.

9. Gasparyan AY, Ayvazyan L, Mikhailidis DP, Kitas GD (2011) Mean platelet volume: a link between thrombosis and inflammation? Curr Pharm Des 17: 47-58. 
Citation: Faruk EM, Eldesoky RE, Mahgoub MY, Mahmoud El.gndy EM, Fouad H (2019) The Blood Cells Ultrastructure Electron Microscopy Changes: Reflection on Systemic Lupus Erythematosus. J Cytol Histol 10: 534. doi:10.4172/2157-7099.1000534

Page 7 of 7

10. Macchi L, Rispal P, Clofent-Sanchez G, Pellegrin JL, Nurden PL, et al. (1997) Anti-platelet antibodies in patients with systemic lupus erythematosus and the primary antiphospholipid antibody syndrome: their relationship with the observed thrombocytopenia. Br J Haematol 98: 336-341.

11. Su F, Xiao W, Yang P, Chen Q, Sun X, et al. (2017) Anti-neutrophil cytoplasmic antibodies in new-onset systemic lupus erythematosus. An Bras Dermatol 92: 466-469.

12. Denny MF, Yalavarthi S, Zhao W, Thacker SG, Anderson M, et al. (2010) A distinct subset of proinflammatory neutrophils isolated from patients with systemic lupus erythematosus induces vascular damage and synthesizes type I Interferons. J Immunol 184: 3284-3297.

13. van der Linden M, van den Hoogen LL, Westerlaken GHA, Fritsch-Stork RDE, van Roon JAG, et al. (2018) Neutrophil extracellular trap release is associated with antinuclear antibodies in systemic lupus erythematosus and anti-phospholipid syndrome. Rheumatology 57: 1228-1234.

14. Burlinson B, Tice RR, Speit G, Agurell E, Brendler-Schwaab SY, et al. (2007) In vivo comet assay workgroup, part of the fourth international workgroup on genotoxicity testing. Mutat Res 627: 31-35.

15. World Medical Association Declaration of Helsinki. Recommendations guiding physicians in biomedical research involving human subjects. JAMA 277: 925-926.

16. Petri M, Orbai AM, Alarcón GS, Gordon C, Merrill JT, et al. (2012) Derivation and validation of the Systemic Lupus International Collaborating Clinics classification criteria for systemic lupus erythematosus. J Arthritis Rheum 64: 2677-2686.

17. Daca A, Czuszyńska Z, Smoleńska Z, Zdrojewski Z, Witkowski JM, et al (2011) Two systemic lupus erythematosus (SLE) global disease activity indexes-the SLE Disease Activity Index and the Systemic Lupus Activity Measure-demonstrate different correlations with activation of peripheral blood CD4+ T cells. Hum Immunol 72: 1160-1167.

18. Winey M, Meehl JB, O'Toole ET, Giddings TH (2014) Conventional transmission electron microscopy. Mol Biol Cell 25: 319-323.

19. Mojgan N, Diana A (2016) The use of isolated peripheral lymphocytes and human whole blood in the comet assay. Protocol Exchange.

20. Møller P (2018) The comet assay: ready for 30 more years. Mutagenesis. 33:1-7.

21. Strober W (2015) Trypan Blue Exclusion Test of Cell Viability. Curr Protoc Immunol 111: A3.B.1-A3.B3.
22. Ashmore L.M, Shopp GM, Edwards BS (1989) Lymphocyte subset analysis by flow cytometry: comparison of three different staining techniques and effects of blood storage. J Immunol Methods 118: 209-215.

23. Ahn, GE, Ramsey-Goldman R (2012) Fatigue in systemic lupus erythematosus. Int J Clin Rheumtol 7: 217-227.

24. Pretorius E, du Plooy J, Soma P, Gasparyan AY (2014) An ultrastructural analysis of platelets, erythrocytes, white blood cells, and fibrin network in systemic lupus erythematosus. Rheumatol Int 34: 1005-1009.

25. Kozora E, Arciniegas DB, Filley CM, West SG, Brown M, et al. (2008) Cognitive and neurologic status in patients with systemic lupus erythematosus without major neuropsychiatric syndromes. Arthritis Rheum 59: 1639-1646.

26. Ellsworth ML, Ellis CG, Goldman D, Stephenson AH, Dietrich HH, et al. (2009) Erythrocytes: oxygen sensors and modulators of vascular tone. Physiology (Bethesda) 24: 107-116.

27. Swadzba J, Iwaniec T, Musial J (2011) Increased level of tumor necrosis factor in patients with antiphospholipid syndrome: marker not only of inflammation but also of the prothrombotic state. Rheumatol Int 31: 307-313.

28. Evans MD, Cooke MS, Akil M, Samanta A, Lunec J (2000) Aberrant processing of oxidative DNA damage in systemic lupus erythematosus. Biochem Biophys Res Commun 273: 894-898.

29. Lunec J, Herbert K, Blount S, Griffiths HR, Emery P (1994) 8Hydroxydeoxyguanosine. A marker of oxidative DNA damage in systemic lupus erythematosus. FEBS Lett 348: 131-138.

30. Bertsias GK, Salmon JE, Boumpas DT (2010) Therapeutic opportunities in systemic lupus erythematosus: state of the art and prospects for the new decade. Ann Rheum Dis 69: 1603-1611.

31. Gasparyan AY, Stavropoulos-Kalinoglou A, Mikhailidis DP, Toms TE Douglas KM, et al. (2010) The rationale for comparative studies of accelerated atherosclerosis in rheumatic diseases. Curr Vasc Pharmacol 8: 437-449.

32. Lee HT, Lin CS, Lee CS, Tsai CY, Wei YH (2014) Increased 8-hydroxy-2'deoxyguanosine in plasma and decreased mRNA expression of human 8oxoguanine DNA glycosylase 1, anti-oxidant enzymes, mitochondrial biogenesis-related proteins and glycolytic enzymes in leucocytes in patients with systemic lupus erythematosus. Clin Exp Immunol 176: 66-77. 